\title{
University Evolution Education: The Effect of Evolution Instruction on Biology Majors' Content Knowledge, Attitude Toward Evolution, and Theistic Position
}

\author{
Justin W. Rice • Joanne K. Olson • James T. Colbert
}

Published online: 2 November 2010

(C) Springer Science+Business Media, LLC 2010

\begin{abstract}
Issues regarding understanding of evolution and resistance to evolution education in the United States are of key importance to biology educators at all levels. While research has measured student views toward evolution at single points in time, few studies have been published investigating whether views of college seniors are any different than first-year students in the same degree program. Additionally, students choosing to major in biological sciences have largely been overlooked, as if their acceptance of evolution is assumed. This study investigated the understanding of evolution and attitude toward evolution held by students majoring in biological science during their first and fourth years in a public research university. Participants included students in a firstyear introductory biology course intended for biological science majors and graduating seniors earning degrees in either biology or genetics. The portion of the survey reported here consisted of quantitative measures of students' understanding of core concepts of evolution and their attitude toward evolution. The results indicate that students' understanding of particular evolutionary concepts is significantly higher among seniors, but their attitude toward evolution is only slightly improved compared to their first-
\end{abstract}

Electronic supplementary material The online version of this article (doi:10.1007/s12052-010-0289-y) contains supplementary material, which is available to authorized users.

J. W. Rice $(\bowtie) \cdot$ J. T. Colbert

Department of Ecology, Evolution and Organismal Biology, Iowa State University,

Ames, IA 50011-3198, USA

e-mail: jwrice@iastate.edu

J. K. Olson

Department of Curriculum and Instruction, Iowa State University,

Ames, IA 50011-3198, USA year student peers. When comparing first-year students and seniors, students' theistic position was not significantly different.

Keywords Science education · Teaching - Biological evolution $\cdot$ Creationism $\cdot$ Acceptance of evolution

\section{Introduction}

Evolution is the core concept of biological science. This is not disputed within the scientific community, but it is quite obviously in question within the public sphere in the United States. By most estimates, the United States does not currently have a majority of voting adults who either understand or agree with evolutionary theory (Miller et al. 2006; Gallup Incorporated 2009). Central to resistance to evolution education are fundamental misconceptions about what science is and how it works (e.g., the "nature of science") that can be seen in accusations that evolution is "just a theory" or is not experimentally "proven," to name a few (Alters and Alters 2001; Luskin 2009).

A widely publicized national survey of 1,484 U.S. adults showed that $39 \%$ held the viewpoint that evolution was "false" (Miller et al. 2006). Other studies have reached the same conclusion (see Table 1) (Ingram and Nelson 2006; Moore and Kraemer 2005; Verhey 2005; Brem et al. 2003; Colburn and Henriques 2006; Eve et al. 2010; Barnes et al. 2009; Losh and Nzekwe 2010). Participants who hold some of the "creationist" viewpoints described in those surveys reject evolution either in whole or in part. That such a large percentage of the public holds views that directly contradict those of the scientific community is evidence of a significant failure to provide effective education in evolutionary theory as well as the nature of science. It is, 
Table 1 Previous studies of rates of acceptance of evolution

\begin{tabular}{|c|c|c|}
\hline Group studied & $\begin{array}{l}\text { Percentage with } \\
\text { creationist } \\
\text { positions }\end{array}$ & Source \\
\hline $\begin{array}{l}\text { College students enrolled in an } \\
\text { upper level biology course in } \\
\text { Evolution }\end{array}$ & 30 & $\begin{array}{l}\text { Ingram and } \\
\text { Nelson } 2006\end{array}$ \\
\hline $\begin{array}{l}\text { High school biology teachers } \\
\text { in Minnesota }\end{array}$ & 30 & $\begin{array}{l}\text { Moore and } \\
\quad \text { Kraemer } \\
2005\end{array}$ \\
\hline $\begin{array}{l}\text { College students enrolled in an } \\
\text { introductory biology course } \\
\text { for biology majors }\end{array}$ & 50 & Verhey 2005 \\
\hline $\begin{array}{l}\text { General student population } \\
\text { attending a large, public } \\
\text { university }\end{array}$ & 59 & $\begin{array}{l}\text { Brem et al. } \\
2003\end{array}$ \\
\hline U.S. adults & 62 & $\begin{array}{l}\text { Miller et al. } \\
2006\end{array}$ \\
\hline $\begin{array}{l}\text { General student populations } \\
\text { from three colleges }\end{array}$ & 64 & $\begin{array}{l}\text { Barnes et al. } \\
2009\end{array}$ \\
\hline $\begin{array}{l}\text { College students majoring in } \\
\text { education }\end{array}$ & 67 & $\begin{array}{l}\text { Losh and } \\
\text { Nzekwe } \\
2010\end{array}$ \\
\hline Christian clergy & 74 & $\begin{array}{l}\text { Colburn and } \\
\text { Henriques } \\
2006\end{array}$ \\
\hline
\end{tabular}

perhaps, the single greatest failure of science education in the history of the United States.

Currently, the majority of data available on this topic is only single-point descriptions of participant understanding and/or attitude and rarely has comparison groups. Unfortunately, such snapshots fail to provide information about whether the education the participants are receiving has any impact, e.g., whether students who leave a program targeted toward understanding biological evolution have understanding or attitudes that are any different than those who enter. Also, while science makes no claims regarding supernatural deities, critics of evolution education have expressed concern that receiving such an education in evolutionary theory will alter students' theistic beliefs, evidence regarding this remains anecdotal (Amanpour 2007; Williams 2009). We need more data on whether university biology majors who graduate have higher understanding of evolution, better attitudes toward evolution, or have theistic positions that are any different than entering students.

A few previous studies have shown a change in understanding and/or attitude as a result of effective instruction in biological evolution. So far, however, those studies have only either examined non-biology majors (Robbins and Roy 2007) or sampled an extremely small population of nineteen first-year biology students (Martin-
Hansen 2008). In both of those studies, issues regarding biological evolution were taught explicitly in the biology classroom. Both studies showed an overall improvement in attitude toward biological evolution after instruction.

University students majoring in biological sciences commonly receive extensive instruction in biology concepts across their program of study. Biological science majors should, upon graduation, have a strong understanding of biological evolution and its central role in the discipline. It appears logical to assume that, of any group on campus, biological science majors should have a propensity toward acceptance of evolution because they have chosen to major in the field. Unfortunately, this assumption cannot be made. Previous studies of biology majors found that approximately $40-50 \%$ do not accept evolution (Verhey 2005; Moore and Cotner 2009), a percentage consistent with the views of the general public (Miller et al. 2006; Gallup Incorporated 2009).

The purpose of this study is to compare university firstyear students' and seniors' understanding of evolution, attitude toward, and acceptance of evolution, and theistic position. Biology majors and genetics majors were selected due to the consistent instruction they receive that addresses biological evolution over the span of their undergraduate degree program. By understanding their content knowledge, their acceptance of evolution as a valid science idea, and their theistic position, we can better understand the role of consistent instruction on these variables and gain important insight into the effectiveness of evolution education.

Specifically, this study was designed to answer the following questions:

1. How, if at all, does student understanding of biological evolution differ between first-year students and seniors in the biology major or the genetics major?

2. How, if at all, does student attitude toward biological evolution differ between first-year students and seniors in the biology major or the genetics major?

3. What is the relationship, if any, between students' theistic position and the amount of evolution instruction they have received?

4. What relationship, if any, exists between students' theistic position and their understanding of evolution concepts?

\section{Study Context and Methodology}

\section{First-Year Participants}

First-year students were recruited for study participation from the biology majors section of an introductory biology course. Enrollment in that section is not exclusive to 
biology majors and genetics majors; however, they comprise the majority of the enrolled students. When students provided informed consent and volunteered to participate, they were directed to the online survey. Participation in the survey was entirely voluntary, and the data collected were kept anonymous.

First-year participants were selected for two reasons: (1) to compare them to the graduating students with regard to knowledge and acceptance of evolution and (2) to provide pre-post-data on the effectiveness of evolution instruction in the introductory biology course in which they were enrolled. First-year student participant responses were collected from students enrolled in an introductory biology course during the fall 2006 semester. Data were collected twice: during the first 14 days of the course and during the final 14 days of the course. The survey was first taken prior to any course-related instruction on the theory of evolution.

\section{Graduating Senior Participants}

Graduating seniors were recruited via an e-mail to all seniors registered as graduating with degrees in biology, genetics, or both. The email requested their participation in an online survey and provided instructions to access the survey. Only those graduating seniors who had declared majors of biology or genetics were included in the study, as those are the only majors at the study site that require completion of an upper-level course in biological evolution.

Due to various factors, including attrition from the major, a lower number of graduating seniors participated in the study than first-year students. To gain a sufficient participant group size to make comparisons, data were collected from graduating seniors during the last fourteen days prior to the official graduation date of the spring 2006, summer 2006, fall 2006, and spring 2007 semesters. These collection times preclude the possibility of any of the same participants being in both the senior and first-year student groups.

\section{Study Context}

The biology major is an interdepartmental major consisting of coursework in principles of biology, ecology, genetics, cell biology, and evolution, followed by upper-level courses in the students' areas of interest. The overall gender proportion of students in the biology major is approximately $60 \%$ female, $40 \%$ male, predominately Caucasian, and over $75 \%$ are from the Midwestern region of the United States. Students begin their four-year program with coursework that addresses biological evolution in the context of introductory biology. The introductory course is described in the course catalog as: "Introduction to the nature of life, including the cellular basis of life; the nature of heredity; evolution; diversity of microbial, plant, and animal life; and principles of ecology. Intended for life science majors." This course is taken by students majoring in biology, genetics, agronomy, microbiology, and numerous other majors, including non-biological majors. Most students who take this course also take the associated lab course where diverse topics, including evolution, are explored in a laboratory setting. Biology and genetics majors are required to take an upper-level course in biological evolution later in their undergraduate experience.

\section{Survey Instrument}

The survey consisted of 15 questions: five questions that tested basic knowledge of evolutionary concepts and ten questions that measured attitude toward evolution, creationism, intelligent design, public policy regarding evolution education, and the nature of science (Supplemental Material Online).

After receiving human subjects approval, the survey was developed over a period of several months by pilot testing items developed by one of the authors (Colbert) and incorporating material from several previous studies (Ingram and Nelson 2006; Moore and Kraemer 2005; Brem et al. 2003; Colburn and Henriques 2006; Lawson and Worsnop 1992; Bishop and Anderson 1990; Demastes et al. 1995). The first five questions of the survey were designed to be similar to a short quiz on basic evolutionary concepts including: the definition of biological evolution, the elements and actions of natural selection, the definition of the phrase "survival of the fittest," and presence of homologous structures in organisms. The second section of the survey asked participants to provide their opinion on various topics in an agree-disagree format on a Likert scale. For example, question 8: "Biological evolution is a valid science idea" and question 10: "Biological evolution is just a theory, and therefore unlikely to be correct." Question 15 was designed elicit the participants' view of the origin of biological diversity on Earth they felt was most congruent with their own. Participant responses to question 15 were then used to identify their relative theistic position. The possible answers were based on the categorization scheme of potential theistic positions toward evolution found in Eugenie C. Scott's book Evolution VS Creationism: An Introduction (Scott 2004). During survey development, the number of possible categories was reduced to five and a "none of the above" response. The potential responses to question 15 are detailed in Table 2. The remainder of the survey included additional questions measuring attitude toward evolution, understanding of the nature of science, and preference toward public education policy. The full survey is provided in the supplemental material available online. 
Table 2 Frequency data for question 15

$\begin{aligned} & \text { 15. Please read all of the following options, then select the one that is closest to } \\ & \text { your perspective. }\end{aligned}$
$\begin{aligned} & \text { 1st-Year pre- } \\ & \text { Instruction }\end{aligned}$ $\begin{array}{ll}\begin{array}{l}1 \text { st-Year } \\ \text { post- } \\ \text { Instruction }\end{array} & \begin{array}{l}\text { Graduating } \\ \text { seniors }\end{array}\end{array}$

\begin{tabular}{|c|c|c|c|c|}
\hline $\begin{array}{l}\text { Creationist } \\
\text { postion }\end{array}$ & $\begin{array}{l}\text { a. The Earth is young }(6,000-10,000 \text { years }) \text {, with each of the six days of Genesis/ } \\
\text { Creation being } 24 \text {-hour days. God created each kind of organism in its present form. }\end{array}$ & $7.3 \%$ & 4.1 & 3.3 \\
\hline $\begin{array}{l}\text { Creationist } \\
\text { postion }\end{array}$ & $\begin{array}{l}\text { b. The Earth is ancient (many millions of years), with each of the six days of } \\
\text { Genesis/Creation being long periods of time (thousands or millions of years). } \\
\text { God created each kind of organism in its present form. }\end{array}$ & 8.5 & 10.7 & 6.6 \\
\hline $\begin{array}{l}\text { Creationist } \\
\text { postion }\end{array}$ & $\begin{array}{l}\text { c. The Earth is ancient (many millions of years). Biological evolution occurs, but } \\
\text { God has intervened at critical points. God created species through the laws of } \\
\text { nature. }\end{array}$ & 28.0 & 28.7 & 19.7 \\
\hline $\begin{array}{l}\text { Evolutionist } \\
\text { postion }\end{array}$ & $\begin{array}{l}\text { d. The Earth is ancient (many millions of years). Biological evolution describes a } \\
\text { natural process that produces species without reliance upon intervention from } \\
\text { God. Biological evolution neither supports nor denies the existence of God. }\end{array}$ & 31.7 & 41.0 & 55.7 \\
\hline \multirow[t]{2}{*}{$\begin{array}{l}\text { Evolutionist } \\
\text { postion }\end{array}$} & $\begin{array}{l}\text { e. The Earth is ancient (many millions of years). Biological evolution occurs as a } \\
\text { natural process to produce species. Biological evolution supports the idea that } \\
\text { God does not exist. }\end{array}$ & 6.1 & 5.7 & 1.6 \\
\hline & $\begin{array}{l}\text { f. None of these options fit my perspective. If you select this answer, please } \\
\text { describe your perspective, in as much detail as you can, in the following text } \\
\text { box. }\end{array}$ & 18.3 & 9.8 & 13.1 \\
\hline
\end{tabular}

Differences between groups were not significant at $p<0.05(N=265 ; F=52.58 ; d f=2,262)$

\section{Data Analysis}

Statistical analyses of data were conducted using ANOVA, ANCOVA, and Chi-square tests. Significance was accepted at the $p<0.05$ level, except where noted. Tukey and Tamhane's tests were conducted as post hoc analyses in ANOVA cases where assumption of homogeneity of variance could not be verified. Chi-square tests were done on all questions. A multivariate vector analysis was performed on the summed responses of questions 1 through 5 by questions 8,10 , and 15 and separated into vectors by instructional level and theistic position. Statistical analyses were performed using both the SPSS and R software packages.

\section{Results}

Eighty-two surveys from the 162 students initially in the introductory biology class $(50.6 \%)$ were completed by the First-year participants prior to evolution instruction. This group is referred to as "1st year Pre-instruction." One hundred and twenty-two surveys from the 153 students completing the class $(79.7 \%)$ were collected after instruction in evolution had occurred. This group is referred to as "1st year post-instruction." A total of 61 of 142 surveys $(42.9 \%)$ were completed by students graduating with degrees in biology or genetics. This group is referred to as "graduating seniors."

Analysis of participants' responses to the first five questions indicates that scores were higher after instruction $(N=265 ; F=52.58 ; d f=2,262 ; p<0.001)$. Each question had only one correct answer; Thus each question was scored either a 0 or a 1 . Correct responses across the five questions were summed with a range of $0-5$. The group means across the first five questions are summarized in Fig. 1.

Question 15 was examined for relationships between participants' theistic position and other variables. For part of the analysis, the answers from question 15 were

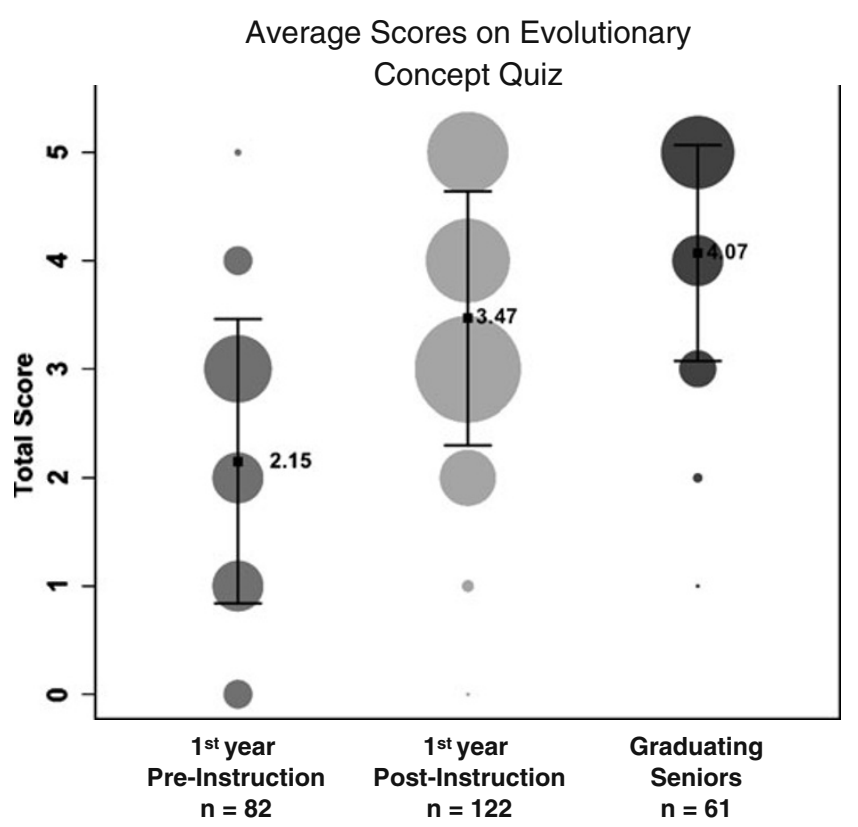

Fig. 1 Average scores between groups are significantly different from each other at $p<0.01$ using Tamhane due to violation of assumption of homogeneity of variances. Bars represent one standard deviation from the mean. Larger circles represent larger numbers of participants earning that total quiz score. $(N=265 ; F=52.58 ; d f=2,262 ; p<0.001)$ 
categorized into either evolutionary positions or creationist positions. Participants who chose any of the first three responses were grouped into the creationist positions category, while participants who chose the fourth or fifth responses were grouped into the evolutionary positions category. Participants who chose the "none of the above" response were left in that category. The possible responses and the resulting frequencies for participant theistic position are reported in Table 2. No significant differences were detected between any of the groups on this variable.

Participant groups and understanding of evolution (the first five items) were examined with a multivariate vector analysis to determine their relationship with the attitudinal data from responses to questions 8, 10, and 15 (Fig. 2). Overall, the participants have a vector of improved understanding of evolution and improved attitude toward evolution. When participants are divided into those with creationist positions and those with evolutionary positions and compared over instructional time, significantly different attitudinal vectors are apparent. Participants with Evolutionary positions show a nearly identical vector to the total overall. Participants with creationist positions, however, show a significantly different vector caused by a decline in

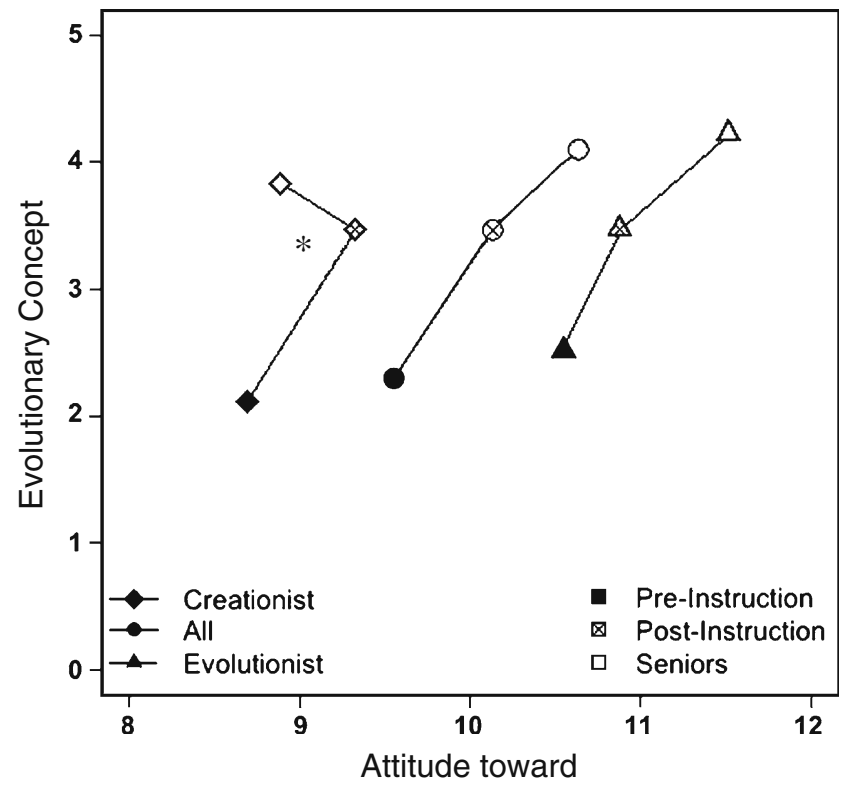

Fig. 2 Multivariate vector analysis of participant understanding of evolution with participant attitude toward evolution with instruction. $X$-axis scale is 0 to 12 , with 0 being the maximum negative attitude toward evolution and 12 being maximum positive attitude toward evolution. Scores of attitude toward evolution are based on an averaged value of responses to questions 8,10 , and 15 by group specified. $Y$-axis number of correct responses to questions $1-5$ separated by instructional level and group specified. ${ }^{*} p<0.01$ (Creationist vector is significantly different from the All and Evolutionist vector). $(N=265 ; F=52.58 ; d f=2,262)$ attitude toward evolution in the graduating senior participant group.

\section{Discussion}

In the study of college biology majors reported here, participant understanding of evolutionary concepts is highest among seniors, and freshmen substantially improve their understanding after taking the initial biology course. This indicates that coursework throughout the degree program is successful in helping students understand this central concept of biology. Each group showed a significant difference, with the largest difference between the firstyear pre-instruction and the first-year post-instruction (Fig. 1). An important caveat, however, is that only in the comparison between first-year participants is the same population of students involved. Not only were the graduating senior participant data collected from a different population of students, but it was also a smaller population. The analysis presented here does not account for the likely attrition from the introductory biology course, from the biology major, and from the university itself, of some participants. These students may have removed themselves for any number of reasons, which are beyond the scope of this research to examine. These participants may or may not have understood evolutionary theory. Keeping that in mind, average student understanding of evolution significantly improved after taking the introductory biology course.

Importantly, results of this study indicate that students' theistic position does not differ across groups, even though understanding and overall acceptance of evolution is higher for students who have completed more coursework in the major. The theistic position held by freshmen did not significantly change after experiencing a course that addressed evolution, and seniors held views that were not statistically different than their freshmen peers despite having had additional coursework in biological evolution. The percentages of freshmen holding creationist positions (43.8\% pre-instruction and $43.5 \%$ post-instruction) are approximately the same as those for the adult population in the United States (Miller et al. 2006; Gallup Incorporated 2009).

One possible interpretation of these data is that the participants are not becoming more atheistic or agnostic over time. It also implies that they are not becoming more religious. This result is of particular interest, as many parents with creationist positions claim that they do not wish their children to lose their religious identity when they are exposed to instruction in evolution (Alters and Alters 2001; Williams 2009).

When group membership is taken into account, the participants' theistic position shows no significant relation- 
ship to the participants' performance on quiz questions related to understanding of evolution concepts. Only $4 \%$ of the variance in quiz score is explained by the responses to question 15 (theistic position), while $25.8 \%$ of the variance in quiz score is explained by participants' instructional level in the program (Pre-Instruction, Post-Instruction, Graduating Senior). This suggests that the participants' educational experience, not their religious preference, is related to their understanding of evolution. These results, along with the significant differences between the average quiz scores of the three groups, suggest that students can learn evolutionary theory regardless of their religious preferences.

Participants who selected the answer: "The Earth is ancient (many millions of years). Biological evolution occurs, but God has intervened at critical points. God created species through the laws of nature" are considered Theistic Evolutionists (Scott 2004) and could feasibly be grouped with the Evolutionary Positions category. The authors grouped these responses with the Young Earth Creationist and Old Earth Creationist responses for two reasons: First, this is consistent with previously published work in this field (Ingram and Nelson 2006; Moore and Kraemer 2005; Brem et al. 2003; Colburn and Henriques 2006; Eve et al. 2010; Barnes et al. 2009; Losh et al. 2010; Moore and Cotner 2009; Lawson and Worsnop 1992; Bishop and Anderson 1990). Second, this answer includes a supernatural cause in the explanation for the diversity of life on Earth. Since science (including the theory of evolution) deals only with natural causes, those who choose this response are, in our estimation, closer to the Young Earth and Old Earth Creationist positions than to the Agnostic or Atheistic positions.

When participant responses are grouped by instructional level and theistic position (Fig. 2), the overall trend is toward increased understanding of evolution and improved attitude toward evolution. This trend is also seen in the participants that self-identify as having more evolutionist positions. In those participants that have more creationist theistic positions, understanding of evolution is higher in groups with more instruction, and attitude toward evolution is also higher, but not to the same degree. This suggests a need to account for the distinct difference between those participants in future studies and may account for the lack of change seen in some previous studies (Alters and Nelson 2002; Chinsamy and Plaganyi 2008). Between the first-year post-instruction and graduating senior "creationist" groups, attitude toward evolution is dramatically lower, nearly at the level prior to any instruction. In the approximately 3.5 years of college attendance separating the postinstruction first-year participants and the graduating senior participants, something may have negatively impacted their views toward evolution. Many explanations could account for this trend, but the pre-instruction and post-instruction participants are a different population than the graduating seniors, and as such, they may have underlying differences that make comparisons difficult. Further research is necessary to determine the effect of this variable over time with confidence.

We acknowledge the limitations of this study. The instructor of the introductory biology course is known to put forth "extra effort" in regard to instruction in evolutionary theory and the nature of science. The effects seen in this study might not be seen to the same degree were a different instructor involved. Attrition of students from the biology major may also affect the results. Students may leave the major for several reasons including: change in major, change in university, loss of funding sources, and dislike/rejection of evolutionary content. This loss may affect the comparison not only between the first-year groups and the graduating seniors but also between the two first-year groups. This attrition of students from the program and the study is an important reason that longitudinal studies of acceptance and understanding of evolution need to be performed. In regard to the senior group, a smaller number of students participated than those in the other groups. While we used conservative statistical procedures to account for the unequal group size, students who completed the survey may not be representative of the population as a whole.

\section{Conclusions}

This study was designed to compare the understanding of first-year and senior biology majors at a large, public Midwestern university regarding their knowledge and acceptance of evolutionary theory and their theistic position. This study has found that student understanding of evolution was higher for groups who had more instruction; attitude toward evolution was higher overall for groups with more instruction, and student theistic position is not significantly different between first-year students before and after taking introductory biology and the graduating seniors. One can surmise, based on these data, that college students taking an introductory biology course can learn evolution while simultaneously improving their attitude toward it and yet not change the foundation of their theistic view.

This study provides evidence to educators that their students, no matter their theistic position, can learn evolutionary concepts. Members of the public, including parents, for whom religious beliefs are important, should see this as evidence that instruction in evolution is not likely causing "religious damage" to their children. Students who think they will not be able to learn evolution effectively due to their beliefs can take this as evidence to the contrary. 
We recognize the need for the same individuals to be monitored throughout their college experience to determine how their thinking changes over time. It has long been established within educational research that long-term longitudinal data is important to evaluate changes in understanding and attitude over time. In addition to collecting long-term longitudinal data on individuals, investigators should also strive to address other areas where our knowledge of evolution education is incomplete. In the authors' experience, many people assume that all (or most) students earning degrees in biology (or related fields) have attitudes/theistic positions that are evolutionist in nature. This is not supported by either this study (Table 2) or previous work (Ingram and Nelson 2006; Moore and Kraemer 2005; Verhey 2005; Brem et al. 2003; Eve et al. 2010; Barnes et al. 2009; Losh et al. 2010).

Just as the assumption is made that biology majors hold favorable views toward evolution, the same assumption is commonly made of biology faculty and instructors. University students are taught biology by a variety of individuals, only a small percentage of whom may be experts or researchers in biological evolution. The extent to which faculty and instructors hold attitudes and perspectives consistent with biological evolution is unknown and may have an effect on their undergraduate students. Misunderstandings of core elements of biological evolution and terminology have been found in refereed publications (Rice et al. 2010). Examination of a sample of high school textbooks produced by faculty shows that while core evolutionary content is accurate and appropriate, in far too many cases, their depiction of the nature of science is inadequate (Abd-El-Khalick et al. 2008; Chiappetta and Fillman 2007). The understanding of the nature of science held by faculty is key, as college biology student acceptance of biological evolution is dependent on the students' understanding of what science is and how science works (Johnson and Peeples 1987).

Far too often, the blame for the problem of inadequate evolution education in the United States is laid solely at the feet of the K-12 education system. While significant improvements to the evolution education of those students can be made, K-12 schools are not the only place where evolution education occurs. University biology programs can have a positive impact on student understanding of evolution, despite students' theistic beliefs. However, much remains to be done to help students accept evolution as a valid science idea, and to understand why scientists use evolutionary theory in their work. Acceptance of evolution as a valid science idea is central to the public education evolution education controversy in the United States. Because an accurate understanding of the nature of science is prerequisite to understanding why scientists use evolutionary theory and how scientists can also hold theistic positions in their private lives, we recommend that research efforts focus on how to effectively address issues in the nature of science, particularly related to evolution, in the undergraduate science curriculum. Perhaps it is time we do more than merely help students understand evolution while letting them reject it as a valid science idea.

Acknowledgements We thank D. Adams for his assistance with statistical analysis and interpretation and A. Heathcote for his assistance in graphical representation. We also thank the anonymous reviewers for the comments and suggestions that led to improvements in this paper.

\section{References}

Abd-El-Khalick F, Waters M, Le A. Representations of nature of science in high school chemistry textbooks over the past four decades. J Res Sci Teach. 2008;45:835-55.

Alters BJ, Alters SM. Defending evolution: a guide to the creation/ evolution controversy. Sudbury: Jones and Bartlett; 2001.

Alters BJ, Nelson CE. Perspective: teaching evolution in higher education. Evolution. 2002;56:1891-901.

Amanpour, C. God's Christian warriors. Available at transcripts.cnn. com (2007). Accessed October 7, 2009.

Barnes RM, Keilholtz LE, Alberstadt AL. Creationism and evolution beliefs among college students. Skeptic. 2009;14(3):13-6.

Bishop BA, Anderson CW. Student conceptions of natural selection and its role in evolution. J Res Sci Teach. 1990;27:415-27.

Brem SK, Ranney R, Schindel J. Perceived consequences of evolution: college students perceive negative personal and social impact in evolutionary theory. Sci Educ. 2003;87:181-206.

Chiappetta EL, Fillman DA. Analysis of five high school biology textbooks used in the United States for inclusion of the nature of science. J Sci Educ. 2007;29:1847-68.

Chinsamy A, Plaganyi E. Accepting evolution. Evolution. 2008;62:248-54.

Colburn A, Henriques L. Clergy views on evolution, creationism, science, and religion. J Res Sci Teach. 2006;43:419-42.

Demastes SS, Good RG, Peebles P. Students' conceptual ecologies and the process of conceptual change in evolution. Sci Educ. 1995;79:637-66.

Eve RA, Losh SC, Nzekwe B. Lessons from the social psychology of evolution warfare: good science alone is not enough. Evol Educ Outreach. 2010;3:183-92.

Gallup Incorporated. On Darwin's birthday, Only 4 in 10 Believe in Evolution. Available at www.gallup.com (2009). Accessed October 7, 2009.

Ingram EL, Nelson CE. Relationship between achievement and students' acceptance of evolution or creation in an upper-level evolution course. J Res Sci Teach. 2006;43:7-24.

Johnson RL, Peeples EE. The role of scientific understanding in college: student acceptance of evolution. Am Biol Teach. 1987;49:93-8.

Lawson AE, Worsnop WA. Learning about evolution and rejecting a belief in special creation: effects of reflective reasoning skill, prior knowledge, prior belief and religious commitment. J Res Sci Teach. 1992;29:143-66.

Losh SC, Nzekwe B. Creatures in the classroom: attitudes and beliefs about fantastic beasts, extraterrestrials, and creationism among education majors. Paper presented at the American Association for Public Opinion Research meetings, Chicago; 2010, May 2010.

Luskin, C. The positive case for design. Available at www.ideacenter. org (2009). Accessed October 7, 2009. 
Martin-Hansen LM. First-year college students' conflict with religion and science. Sci Educ. 2008;17:317-57.

Miller JD, Scott EC, Okamoto S. Public acceptance of evolution. Science. 2006;313:765-6.

Moore R, Cotner S. The creationist down the hall: does it matter when teachers teach creationism? Bioscience. 2009;59:429-35.

Moore R, Kraemer K. The teaching of evolution and creationism in minnesota. Am Biol Teach. 2005;67:457-66.

Rice JW, Warner DA, Kelly CD, Clough MP, Colbert JT. The theory of evolution is not an explanation for the origin of life. Evolution Education and Outreach (2010). 2010.
Robbins JR, Roy P. The natural selection: identifying \& correcting non-science student preconceptions through an inquiry-based, critical approach to evolution. Am Biol Teach. 2007;69:460-6.

Scott EC. Evolution vs. creationism: an introduction. Westport: Greenwood; 2004.

Verhey SD. The effect of engaging prior learning on student attitudes toward creationism and evolution. Bioscience. 2005;55:9961003.

Williams ME. Kirk Cameron monkeys with Darwin. Available at www.salon.com (2009). Accessed October 7, 2009. 